\title{
DOS PRONUNCIAMIENTOS JUDICIALES RELACIONADOS Y DECISIVOS PARA EL AVANCE DEL RECONOCIMIENTO MUTUO DEL REGLAMENTO 805/2004: LA SENTENCIA DEL TC 26/2020, DE 24 DE FEBRERO Y EL AUTO DE LA AP DE GIRONA 243/2020, DE 10 DE JUNIO
}

MAYTE ECHEZARRETA FERRER'

mtechezarret@uma.es

M. áNGELES RODRÍGUEZ VÁZQUEZ²

rodriang@us.es

Cómo citar/Citation

Echezarreta Ferrer, M. y Rodríguez Vázquez, M. a Á. (2021). Dos pronunciamientos judiciales relacionados y decisivos para el avance del reconocimiento mutuo del Reglamento 805/2004: la sentencia del TC 26/2020, de 24 de febrero y el auto de la AP de Girona 243/2020, de 10 de junio. Revista de Derecho Comunitario Europeo, 68, 279-307. doi: https://doi.org/10.18042/cepc/rdce.68.09

\section{Resumen}

En este trabajo se analizan dos pronunciamientos judiciales, la STC 26/2020, de 24 de febrero y el Auto de la AP Girona 243/2020, de 10 de junio, que vienen a confirmar que solo puede certificarse como Título ejecutivo europeo una resolución dictada en rebeldía si, en el proceso de origen, se han cumplido las normas mínimas establecidas en el capítulo III del Reglamento 805/2004. La supresión de los controles de la resolución en el Estado miembro de ejecución debe estar inseparablemente vinculada a la existencia de una garantía suficiente de que se observen los derechos de la defensa. El órgano de la ejecución solo puede suspender la ejecución mientras se resuelve la impugnación en origen, como sucede en las resoluciones comentadas.

\footnotetext{
1 Profesora Titular de Derecho Internacional Privado (Universidad de Málaga).

2 Profesora Titular de Derecho Internacional Privado (Universidad de Sevilla).
} 
Palabras clave

Título ejecutivo europeo; normas mínimas; derechos de defensa.

\section{TWO DECISIVE JUDICIAL PRONOUNCEMENTS FOR THE AVANCEMENT OF MUTUAL RECOGNITION OF REGULATION 805/2004: JUDGMENT OF THE SPANISH CONSTITUTIONAL COUR 26/2020, 24 FEBRUARY AND GIRONA PROVINCIAL COURT ORDER 243/2020, 10 JUNE}

\section{Abstract}

In this article two judicial pronouncements are analyzed, Judgment of the Spanish Constitutional Court 26/2020, 24 February and Girona Provincial Court Order 243/2020, 10 June, that confirm that a judgment delivered in absentia of the debtor shall be certified as a European Enforcement Order if the Court proceeding in the Member State of origin met the requirements as set out chapter III of Regulation $805 / 2004$. The abolition of any checks in the Member State of enforcement is inextricably linked to and dependent upon the existence of a sufficient guarantee of observance of the rights of the defense. The competent court in the Member State of enforcement may stay the enforcement proceedings while the challenge is resolved in Member State of origin, as it happens in the commented judicial resolutions.

\section{Keywords}

European Enforcement Order; minimum standards; rights of the debtor.

\section{DEUX DÉCISIONS JUDICIAIRES DÉCISIVES POUR L'AVANCEMENT DE LA RECONNAISSANCE MUTUELLE DU RÈGLEMENT 805/2004: ARRÊT DE LA COUR CONSTITUTIONNELLE 26/2020, DU 24 FÉVRIER ET DE LA COUR PROVINCIALE GIRONA 243/2020, DU 10 JUIN}

\section{Résumé}

Dans ce travail deux décisions judiciaires sont analysées, l'arrêt de la Cour constitutionnelle 26/2020, du 24 février et de la Cour provinciale de Girona 243/2020, du 10 juin, qui confirment qu'une résolution rendue par contumace peut être certifiée que si les normes minimales du chapitre III ont été respectées dans la procédure de l'État membre d'origine. La suppression de tout contrôle dans l'État membre d'exécution est indissolublement liée et subordonnée à la garantie suffisante du respect des droits de la défense. L'autorité compétente dans l'État membre d'exécution peut suspendre la procédure d'exécution pendant que la contestation est résolue dans l'État membre d'origine, comme cela se passe dans les résolutions commentées.

\section{Mots clés}

Titre exécutoire européen; normes minimales; droit de la défense. 


\section{SUMARIO}

I. INTRODUCCIÓN. II. LOS RETOS Y LAS OPORTUNIDADES QUE PLANTEÓ DESDE EL INICIO EL REGLAMENTO 805/2004. III. NOVEDADES JUDICIALES DE 2020 EN LA APLICACIÓN DEL REGLAMENTO 805/2004: 1. España como Estado certificador de títulos ejecutivos europeos en virtud del reglamento: la STC 26/2020, de 24 de febrero: 1.1. Antecedentes. 1.2. Los dos recursos de amparo: 1.2.1. Recurso de amparo núm. 4657/2014. 1.2.2. Recurso de amparo núm. 442/2015. 1.3. El comportamiento del tribunal inglés ante la solicitud de ejecución del TEE. 1.4. Fallo del TC: 1.4.1. Interés jurídico y pedagógico de la sentencia del TC. 1.4.2. Priorización de la notificación personal para la ejecución de la sentencia en España. 1.4.3. Exigencias de la notificación en el proceso español para la ejecución en otro Estado de la UE. 1.4.4. ¿̇Por qué solicita el demandante la certificación del auto despachando la ejecución y no la resolución declarativa de la que trae causa? 2. España como Estado ejecutor de títulos ejecutivos europeos en virtud del reglamento. IV. CONCLUSIONES. BibLIOGRAFía.

\section{INTRODUCCIÓN}

Nos ha parecido oportuno que tras la sentencia del Tribunal Constitucional 26/2020, de 24 de febrero $^{3}$ (en adelante, la STC), quienes, como las autoras de este comentario, en alguna ocasión nos hemos acercado al estudio del Reglamento 805/2004 retomemos lo publicado para valorar nuestras conclusiones de aquel momento a la luz de la actualidad (Echezarreta Ferrer, 2020; Rodríguez Vázquez, 2005, Rodríguez Vázquez, 2006).

Un breve repaso doctrinal de los retos y oportunidades, y de los temores y expectativas que suscitaba este reglamento, nos servirá de punto de arranque. A partir de aquí abordaremos las novedades jurisprudenciales que nos ha dejado 2020 desde la perspectiva de la práctica española y de la extranjera relacionada. Aquí es donde cobra especial relevancia, de un lado, la STC, no

ECLI:ES:TC:2020:26.

4 Reglamento (CE) núm. 805/2004 del Parlamento Europeo y del Consejo, de 21 de abril de 2004, por el que se establece un título ejecutivo europeo para créditos no impugnados, DO, L 143, de 30 de abril de 2004, p. 15. 
solo por lo que interpreta, sino por lo que aporta al funcionamiento bilateral intraeuropeo del reconocimiento mutuo (art. 81.2 TFUE) que instrumenta el reglamento. Y, por otra parte, y directamente relacionado con la STC, aludiremos al auto de la AP de Girona de 10 de junio de 20205, dictado unos meses después, aunque en el escenario de la ejecución en España, rectius, de la suspensión de la ejecución de la resolución extranjera certificada en Bélgica como título ejecutivo europeo. Esta resolución viene a confirmar la otra cara del pronunciamiento de la STC, como se explicará posteriormente. La Audiencia Provincial de Girona realiza similares esfuerzos interpretativos a los que realizó el juez inglés como Estado ejecutor en el caso que resuelve el TC. Todo ello en clara armonía con los límites marcados en las también recientes sentencias del TEDH de 15 de diciembre de $2020^{6}$ y de 19 de enero de $2021^{7}$, en cuanto a las exigencias de la notificación al demandado derivadas del art. 6 del Convenio Europeo de Derechos Humanos.

Finalmente aprovecharemos la oportunidad que nos brinda este comentario para plantear algunas quiebras del sistema, fruto quizás de la timidez y los temores del momento en que se promulgó el reglamento o por su propia condición de prueba piloto. Hoy, ya con quince años de aplicación, el reglamento merece ocupar un espacio algo más consolidado en el escenario de la cooperación judicial civil y, en particular, del reconocimiento mutuo, aunque paliando algunas aristas.

\section{LOS RETOS Y LAS OPORTUNIDADES QUE PLANTEÓ DESDE EL INICIO EL REGLAMENTO 805/2004}

Con el Reglamento (CE) núm. 805/2004, del Parlamento Europeo y del Consejo de 21 de abril de 2004, por el que se establece un título ejecutivo europeo para créditos no impugnados, el legislador europeo daba el primer paso para la consecución del principio de reconocimiento mutuo, al suprimirse el exequátur en el ámbito patrimonial. La solución fue realmente novedosa aunque con un alcance muy limitado y concebida como antesala de los trabajos de reforma del, por entonces, Reglamento 44/2001 (Bruselas I). De ahí puede entenderse que el título ejecutivo europeo, junto con el proceso monitorio europeo y el proceso de escasa cuantía, fuesen calificados, por el propio legislador europeo, como «reglamentos de primera generación».

\footnotetext{
AAP de Girona 243/2020, de 10 de junio, Cendoj: 17079370012020200212.

Karesvaara and Njie c. Spain, ECLI:CE:ECHR:2020:1215JUD006075015.

Klopstra c. Spain, ECLI:CE:ECHR:2021:0119JUD006561016.
} 
La aprobación de este instrumento supuso toda una revolución en los postulados de la eficacia extraterritorial de resoluciones judiciales extranjeras puesto que no solo se elimina el procedimiento de exequátur, sino cualquier control de la resolución en el Estado miembro de ejecución (incluido el orden público). Además era la primera vez que en un reglamento se introducen «normas procesales mínimas aplicables a los procedimientos» (el germen de la deseada por muchos unificación procesal europea), aunque no de aplicación directa y obligatoria, cuyo estricto cumplimiento por el juez de origen avala el respeto de los derechos de defensa del deudor y justifica la no fiscalización a posteriori de la resolución. Se trata de una regulación que protege no solo el derecho del acreedor a cobrar de forma rápida su crédito, sino también el derecho de defensa del deudor. Así las cosas en 2004 y con el horizonte del principio de reconocimiento mutuo, el reglamento puso el techo muy alto.

No obstante, esta iniciativa solo se diseñó para unos supuestos muy reducidos: en primer lugar, solo afecta a las resoluciones dictadas sobre un crédito no impugnado, siempre que se hayan cumplido los presupuestos establecidos en el reglamento como segunda condición, y, por último, que se hayan certificado por el juez de origen como título ejecutivo europeo. Dicho con otras palabras, el título ejecutivo europeo es un certificado que acredita que se han respetado todas las garantías por el juez de origen y, por ende, se han cumplido todos los presupuestos que el reglamento exige para que la resolución goce de fuerza ejecutiva directa o «declaración de ejecutividad automática» (Garau Sobrino, 2004:91-116; Jiménez Blanco, 2018: 101-125).

El reglamento describe qué debe entenderse por crédito no impugnado, planteándose serios problemas cuando el deudor en el proceso de origen mantuvo una actitud pasiva [letras b) y c) del art. 3.1] puesto que, tratándose de sentencias dictadas en rebeldía o en procedimientos sumarios de cobro, hay que velar por el pleno respeto del derecho de defensa del deudor, es decir, que su actitud pasiva se deriva de una decisión consciente y no debida a una lesión del derecho de defensa porque no tuvo conocimiento del procedimiento entablado contra él ${ }^{8}$. Y precisamente por ello el reglamento establece que, en dichos supuestos, debieron haberse cumplido en el proceso de origen los requisitos procesales que se establecen en el conjunto de normas mínimas del capítulo III.

Solo puede entenderse la limitación del ámbito de aplicación del reglamento a los créditos no impugnados por los temores que la supresión del

8 El TJUE ha interpretado el concepto de crédito no impugnado del art. 3.b) en la Sentencia de 16 de junio de 2016, asunto C-511/14, Pebros Servizi (ECLI:EU:C: 2016:448). Véase comentario de Rodríguez Vázquez (2016b: 1-7). 
exequátur planteaba y por la reticencia a dejar todo el control de cualquier resolución en manos del juez de origen. En aquel momento, y concebido el título ejecutivo europeo como proyecto piloto, se consideró necesario restringirlo a supuestos muy concretos en los que existen garantías de que el deudor ha admitido el crédito. Ahora bien, la práctica ha demostrado que reducir de esta forma la operatividad del reglamento plantea problemas pues en muchas ocasiones, y para evitar la certificación, se impugna de forma artificiosa el crédito, lo que provoca un alto consumo procesal. Como afirma Garcimartín Alférez, no parece justificado que se incluyan todos los créditos no impugnados en los que no compareció el deudor y que en cambio se mantengan fuera de su ámbito de aplicación los supuestos de oposición del deudor (en los que sí hubo comparecencia), pues si hubo oposición del deudor es difícil que se produzca una vulneración del derecho de audiencia (Garcimartín Alférez, 2006: 59).

En líneas generales las normas procesales mínimas enumeran un conjunto de formas en las que debió notificarse al deudor el escrito de incoación o documento equivalente (arts. 13 y 14); establecen una serie de indicaciones que deben constar en dicho documento para proporcionar al deudor la debida información en relación con el crédito (arts. 16 y 17) ${ }^{9}$; regulan las condiciones que permiten la subsanación del incumplimiento de las normas mínimas (art. 18); y prevén la necesaria posibilidad para el deudor de poder solicitar, conforme a la legislación del Estado miembro de origen, la revisión de la resolución ante un órgano jurisdiccional de dicho Estado en determinadas circunstancias excepcionales en las que el deudor, por causas ajenas a su voluntad, no tuvo conocimiento del proceso iniciado contra él o no pudo impugnar el crédito por causas de fuerza mayor (art. 19) ${ }^{10}$. En suma, su finalidad no es otra que garantizar que el deudor tuvo conocimiento del

9 El TJUE en la Sentencia de 28 de febrero de 2018, asunto C-289/17, Collect Inkasso y otros (ECLI:EU:C:2018:133), ha establecido que la información que debe facilitarse al deudor conforme al art. 17 del Reglamento es de obligado cumplimiento.

10 Como afirmó el TJUE en la Sentencia de 17 de diciembre de 2015, asunto C-300/14, Imtech Marine Belgium (ECLI:EU:C:2015:825), el reglamento no impone a los Estados miembros establecer en su derecho interno un procedimiento de revisión como el previsto en el art. 19 sino que los recursos previstos en las distintas legislaciones internas deben cumplir las exigencias de esa disposición, debiéndose tratar de un recurso que permita una revisión plena de la resolución, tanto desde el punto de vista jurídico como fáctico. Véase comentario de Rodríguez Vázquez (2016a: 1-11). En nuestro ordenamiento, aunque la Disposición final $21^{\text {a }}$ LEC no hace referencia a este procedimiento de revisión, España ha comunicado que podrá llevarse a efecto por vía de la rescisión de sentencias firmes a instancia del demandado rebelde (art. 501 LEC). 
procedimiento entablado en su contra, del crédito, de los requisitos para su participación activa en los procedimientos para impugnar el crédito así como de las consecuencias que se derivarían de su actitud pasiva.

Ahora bien, las normas mínimas establecidas por el reglamento no implican la armonización de los derechos procesales de los Estados miembros, ya que se deja a la discreción de los mismos la facultad de adaptar sus legislaciones a dichos requisitos en el supuesto de que lo consideren necesario (considerando 19). La consecuencia que se derivaría de una falta de conformidad de la legislación nacional con estas normas mínimas sería, como ha confirmado el TJUE, la no certificación de la resolución como título ejecutivo europeo $^{11}$. La falta de obligatoriedad o imperatividad de dichas normas mínimas fue considerada, desde primera hora, como «el talón de Aquiles del Reglamento» ${ }^{12}$, pues provoca una aplicación asimétrica del mismo entre los distintos Estados miembros (UE-Dinamarca) según sus normas procesales internas las incorporen o no. Por ello nos planteamos si no debería revisarse este extremo en el futuro reconociéndole fuerza vinculante directa para supuestos transfronterizos, asegurando así las garantías en origen de una resolución nacional cuyo destino sea la circulación entre los Estados miembros.

Cumplidos todos los presupuestos, y si el acreedor lo solicita, el órgano de origen certificará la resolución como título ejecutivo europeo (certificación que siempre tiene carácter jurisdiccional pues exige rigurosas comprobaciones y no un examen puramente formal) ${ }^{13}$. Contra la expedición de un certificado de título ejecutivo europeo no cabrá recurso alguno (art. 10.4), aspecto que fue el más discutido durante la elaboración del reglamento y que ha suscitado muchas críticas por parte de la doctrina (Rodríguez Vázquez, 2005: 69-72 y bibliografía citada). La única posibilidad que tiene el deudor es solicitar al órgano jurisdiccional de origen la rectificación o revocación del certificado de título ejecutivo europeo (art. 10). La rectificación tendrá lugar cuando, debido a un error material, haya discrepancias entre la resolución y el certificado; y

11 Sentencia de 17 de diciembre de 2015, asunto C-300/14, Imtech Marine Belgium (ECLI:EU:C:2015:825).

12 Dictamen del Comité Económico y Social, DO C 85, de 8 de abril de 2003, p. 7.

13 Así lo ha afirmado el TJUE en las ya citadas sentencias Imtech Marine Belgium y Pebros Servizi. En España no hay problemas porque como dispone la Disposición final $21^{\text {a }}$ LEC «la competencia para certificar un título ejecutivo europeo corresponde al mismo tribunal que dictó la resolución». En cambio, la «expedición del certificado» es un acto formal que no tiene que realizar necesariamente un juez ya que, en la práctica, consiste en rellenar espacios y cumplimentar los casilleros recogidos en el Anexo I del reglamento. Por eso dicha expedición puede encomendarse al secretario judicial (letrado de la administración de justicia). 
se revocará cuando la emisión del certificado sea manifiestamente indebida, es decir, se concedió desacertadamente teniendo en cuenta los requisitos del reglamento (lo que permitirá, a nuestro juicio, al órgano jurisdiccional de origen revisar el cumplimiento de los requisitos para la certificación de la resolución como TEE) $)^{14}$. Con esta regulación no solo se concentra el control de las garantías del respeto del derecho de defensa en origen, sino que se reafirma la responsabilidad del deudor de tener que defenderse ante el órgano competente impugnando la resolución o solicitando la revocación del certificado cuando la resolución no debió certificarse como TEE. Asistimos a la máxima consagración de la necesidad de agotar todas las posibilidades de defensa en origen ${ }^{15}$ que termina en el recurso de amparo ante el Tribunal Constitucional español ${ }^{16}$ o, en su caso, ante el TEDH.

La resolución certificada como TEE se ejecutará directamente y solo puede denegarse dicha ejecución si existe inconciliabilidad de resoluciones (art. 21) o la existencia de algún convenio internacional (en los términos que señala el art. 22) ${ }^{17}$. El juez del Estado miembro de ejecución podrá, a instancia del deudor, limitar o suspender la ejecución si concurre alguna de las situaciones previstas en el art. 23. Y es aquí donde, a nuestro juicio, debe residir la esencia del reconocimiento mutuo, como veremos luego en las resoluciones objeto de comentario. La concentración del control de la resolución en origen tiene que compensarse con la suspensión de la ejecución, suspensión que no solo debiera ser a instancia de parte sino también de oficio, cuando el juez

14 En el caso de nuestro ordenamiento jurídico la Disposición final $21^{\text {a }}$ LEC establece que el procedimiento de rectificación de errores se resolverá en la forma prevista en los tres primeros apartados del art. 267 LOPJ; y el de revocación se tramitará y resolverá de conformidad con lo previsto para el recurso de reposición previsto en la LEC, con independencia del orden jurisdiccional al que pertenezca el tribunal.

En palabras de Garcimartín Alférez (2006: 196), al obligar al demandado a agotar su defensa en el Estado de origen, el reglamento establece «una regla de preclusión». Véase al respecto el reciente estudio de Cuartero Rubio (2020).

16 Cuartero Rubio (2019: 225-237) reivindica el papel del TC como juez de la Unión y propone en su trabajo un entendimiento del recurso de amparo que maximice sus posibilidades de actuación para asegurar un funcionamiento ajustado a las necesidades del reconocimiento mutuo pero que respete las particularidades del sistema español de amparo, por tanto, en la medida en que el marco legal del recurso de amparo lo permita. Ilustra esta tesis con el ejemplo de la especial trascendencia constitucional, requisito de admisión cuya configuración legal, construida sobre conceptos jurídicos abiertos y un catálogo abierto de causas, lo consentiría.

17 También podrán oponerse los motivos de oposición previstos en la LEC en la medida que no sean incompatibles con los del Reglamento. 
de la ejecución apreciase que la certificación de la resolución se realizó con manifiesta infracción de los derechos de defensa y se encuentre en revisión en origen.

La desaparición de toda referencia al orden público como motivo de denegación suscitó gran debate y cierto rechazo por parte de un sector de la doctrina (entre otros, González Campos, 2005) ${ }^{18}$. Ahora bien, frente a esta crítica siempre hemos sostenido que el orden público desaparece de la fase de ejecución, pero no de la regulación del reglamento, al estar recogido en la regulación de las normas procesales mínimas, es decir, pasa del juez de ejecución al juez de origen. Un dato que no puede obviarse es que el reglamento era consciente de que la rápida protección del derecho de crédito no podía conseguirse a costa de un sacrificio de los derechos de la defensa y por ello cuando la resolución fue dictada en ausencia del deudor en el procedimiento de origen «la supresión de los controles en el Estado miembro de ejecución debe estar inseparablemente vinculada y sujeta a la existencia de una garantía suficiente de que se observen los derechos de defensa» (considerando 10). De este modo, el reglamento tiene en cuenta los derechos fundamentales, en especial el derecho a un proceso justo y a la tutela judicial reconocido en el art. 47 de la Carta de los Derechos Fundamentales de la Unión Europea (considerando 11). Si la práctica ha demostrado que en la materia patrimonial el orden público que ha intervenido ha sido el procesal y si la regulación de las normas mínimas tiene como finalidad garantizar el derecho del deudor a su defensa y a participar en el proceso, consideramos que la desaparición del orden público se ha compensado con dicha regulación. Ese conjunto de normas (que expresan la dimensión procesal del orden público) actúa como presupuesto de la certificación de la resolución como título ejecutivo europeo. El limitado ámbito de aplicación del reglamento y el estricto cumplimiento de las normas procesales mínimas, avalan la fórmula elegida en materia de protección de los derechos de la defensa (en sentido análogo, entre otros, Biagioni 2007: 213; Garcimartín Alférez, 2006: 186; Seatzu, 2008: 67).

Y el tiempo nos ha dado la razón. De un lado, porque cuando se planteó la reforma del Reglamento «Bruselas I» quedó claro que estos argumentos no podían aplicarse por analogía y que la supresión del exequátur debía acompañarse de ciertas salvaguardas en el Estado miembro de ejecución. Una supresión del exequátur en sentido amplio en el ámbito de aplicación del reglamento habría exigido, a nuestro juicio, una previa armonización de

18 Como afirma Gascón Inchausti (2017: 141), donde se conserva el control del orden público, como en el Reglamento «Bruselas I bis», es testimonial, una simple cláusula de cierre del sistema de escasa o nula aplicación. 
ciertas normas procesales que permitiese al tribunal requerido confiar en el desarrollo del proceso de origen y en que la resolución fue dictada sin lesión del derecho de defensa. Por otra parte, porque la jurisprudencia, tanto del TJUE como la nacional, afirma de forma reiterada que en el Reglamento $805 / 2004$ la supresión del exequátur no se ha realizado a costa de un sacrificio de los derechos de defensa.

Cuestión distinta a valorar es si tras estos quince años de vida las ventajas de toda esta regulación han sido realmente aprovechadas, sobre todo tras las nuevas soluciones que se establecieron en el Reglamento 1215/2012. Quizás es el momento de plantearse nuevas propuestas para avanzar en el principio de reconocimiento mutuo.

\section{NOVEDADES JUDICIALES DE 2020 EN LA APLICACIÓN DEL REGLAMENTO 805/2004}

\section{ESPAÑA COMO ESTADO CERTIFICADOR DE TÍTULOS EJECUTIVOS EUROPEOS EN VIRTUD DEL REGLAMENTO: LA STC 26/2020, DE 24 DE FEBRERO}

Hasta 2020 la práctica española de la aplicación del Reglamento $805 / 2004$ desde la perspectiva certificadora, se ha caracterizado por la ausencia de litigiosidad. Sin embargo, junto a todas las sorpresas que nos sorprendía el año, tenemos que mencionar la STC 26/2020, de 24 de febrero, de enorme relevancia por lo que aporta al avance del principio del reconocimiento mutuo del art. 81 TFUE, al confirmar la trascendencia del control de las garantías procesales por parte del Estado de origen antes de poner en libre circulación por la UE una resolución judicial.

\subsection{Antecedentes}

Como ya han explicado Barcala Fernández de Palencia (2020: 1-3) y Marchal Escalona (2020: 32-33) y también detalla la propia sentencia del TC, todo comenzó cuando el ilustrador español, residente en Burgos, Gerardo Moreno de la Hija reclamó a la mercantil The Quaid Project Limited, a D. Ch.F. Carandini Lee y a D. Juan F. Aneiros Rodríguez (de origen español, yerno de C.F. Carandini Lee y gestor de la web Christopherleeweb.com), el pago de una indemnización por haber utilizado una pintura realizada por él para la difusión en DVD de una película, sin contar con su permiso y sin haber abonado por su utilización precio alguno. Al parecer, entre las partes existía un contrato de colaboración firmado en 2003, previa autorización del 
Sr. Lee, para diseñar la portada de la edición en DVD del filme Jinnah, una coproducción británico-paquistaní de 1998 sobre la fundación del Pakistán moderno y en la que Christopher Lee interpreta al protagonista, Mohamed Alí Jinnah ${ }^{19}$. Sin embargo, en algún momento de las actuaciones se aporta un contrato firmado por el demandante el 17 de febrero de 2004, denominado Work for Hire Agreement, en virtud del cual el demandante cedió la totalidad de los derechos intelectuales y de explotación de su obra a uno de los demandados originalmente con el Sr. Lee, por un precio total de 900 euros, extremo que hasta ahora no ha sido objeto del debate.

La demanda planteada en 2007 ante el Juzgado de lo Mercantil núm. 1 de Burgos, lo era sobre la titularidad de los derechos de explotación de obra artística, y además reclamaba daños y perjuicios por el uso indebido de la obra, sin que nunca se hubiera planteado cuestión alguna sobre la competencia judicial internacional de los tribunales españoles o sobre la ley aplicable a la reclamación. La demanda terminó en sentencia dictada en rebeldía el 6 de marzo de 2009, sin determinación de cantidad líquida: «[...] a indemnizar al demandante en los daños y perjuicios materiales causados, atendiendo a la remuneración que hubiera percibido de haber autorizado la explotación el demandante, cuya cantidad se fijará en el momento procesal oportuno, más intereses legales».

Según argumentaba la defensa del ejecutado, los demandados tenían su domicilio en el Reino Unido y el juzgado no había intentado la notificación personal del auto que despachó la ejecución al Sr. Lee de ninguna manera, puesto que las comisiones rogatorias en su día cursadas mediante correo certificado internacional con acuse de recibo se dirigieron a personas distintas. En concreto, y tal como consta en la STC, a la mercantil Christopher Lee Web a través de su representante, en el domicilio designado por el ejecutante, y a la mercantil The Quaid Project Ltd. De otro lado, se argumentaba, que no se había realizado la más mínima diligencia de averiguación del domicilio del demandante en amparo, hasta el punto de que el Juzgado de lo Mercantil núm. 1 de Burgos acordó la inmediata notificación por edictos a solicitud de la parte ejecutante.

La demanda de ejecución del título judicial se interpuso el 24 de septiembre de 2009, ante el Juzgado de lo Mercantil núm. 1 de Burgos, en la que, entre otros particulares, se presenta relación de daños y perjuicios por un monto total de $710000 €$, aparte intereses y costas, fundando la solicitud en lo prevenido en los arts. 712 y siguientes LEC. Sin embargo, el Juzgado de

19 Las imágenes y una crónica periodística del asunto se recogen en el diario El País, 26 de enero de 2012, https://bit.ly/3bv2GR2 (consultado el 1 de enero de 2021). 
lo Mercantil núm. 1 de Burgos no siguió la tramitación prevista en los arts. 713 y ss. LEC, sino que de manera directa encauza la solicitud de determinación de daños y perjuicios por el cauce de la ejecución dineraria (arts. 571 y siguientes LEC), considerando el auto que despacha la ejecución la cantidad que se reclama como determinada y líquida, no siendo así. Tras la solicitud de embargo de los bienes de los demandados sitos en territorio español y ante la posibilidad de hacerlo también respecto de los bienes que se encontraran en el extranjero, se certificó el 13 de junio de 2011 como TEE, el auto de 13 de octubre de 2009 despachando ejecución ${ }^{20}$. Según argumentaba la defensa del Sr. Lee, de conformidad con los arts. 3.1, 4.1, 4.2, 5 y 6.1 del Reglamento $805 / 2004$, en relación con el art. 517 LEC, dicho auto no podía certificarse como TEE, sino solo la sentencia previa que dio lugar a él.

\subsection{Los dos recursos de amparo}

\subsubsection{Recurso de amparo núm. $4657 / 2014$}

Se recurrió el Auto del Juzgado de lo Mercantil núm. 1 de Burgos de fecha 3 de junio de 2014, dictado en el procedimiento de ejecución de título judicial núm. 695/2009, que resolvió no haber lugar a declarar la nulidad de actuaciones desde el dictado del auto de 26 de octubre de 2009, que despachaba la ejecución. Es en este segundo procedimiento donde el demandante señaló que sus daños y perjuicios ascendían a $710000 €$, más un presupuesto de gastos y costas de $213000 €$. El cálculo de la compensación de $710000 €$, por la explotación no autorizada de la obra del demandante, es parte de este recurso de amparo núm. 4657/2014.

Se pretendía, pues, que se declarase la vulneración del derecho a la tutela judicial efectiva del art. 24.1 CE, en cuanto a la defensa del derecho a un proceso con todas las garantías, a ser oído en el proceso, al principio de contradicción, de audiencia bilateral e igualdad de armas, a la inmutabilidad e intangibilidad de las sentencias firmes y a la ejecución de las resoluciones judiciales en sus propios términos. Para proceder al pleno restablecimiento del derecho fundamental, se requería la nulidad del auto de 3 de junio de 2014 mencionado, así como del auto de 26 de octubre de 2009 que acordó el despacho de ejecución y de las restantes actuaciones subsiguientes, especialmente las resoluciones que acordaban el emplazamiento del Sr. Lee por edictos.

20 Rectificado el 14 de octubre de 2013 en cuanto a los nombres de los demandados y para incluir una cantidad de costas. 
El recurrente denuncia también que el juzgado siguió el cauce procesal de la ejecución de los arts. 571 y siguientes LEC cuando procedía el de los arts. 712 y ss. LEC y conecta esta inadecuación del procedimiento a una vulneración del derecho a un proceso con todas las garantías, invocando el art. 24.1 CE en lugar, a juicio del TC, del más idóneo art. 24.2 CE, que es el que la doctrina constitucional asocia a las denuncias relativas a la inadecuación del procedimiento seguido en instancia.

El recurso de amparo fue admitido a trámite por resolución de 30 de noviembre de 2015.

\subsubsection{Recurso de amparo núm. $442 / 2015$}

Se impugnaron tanto el auto de 3 de junio de 2014 del Juzgado de lo Mercantil núm. 1 de Burgos desestimando la petición de revocación de la Certificación de Título Ejecutivo Europeo (en adelante, CTEE) promovida al amparo del art. 10.1 b) del Reglamento 805/2004, y el auto de 31 de julio de 2014 del mismo juzgado desestimando el recurso de reposición presentado frente al anterior auto de 3 de junio de 2014. Se interesaba que se declarara la nulidad de los referidos autos, restableciendo al Sr. Lee en sus derechos mediante la anulación de las resoluciones que acuerdan emitir y las que emiten el CTEE, que habría de ser anulado.

Se alegó la vulneración del art. $24 \mathrm{CE}$ en varias de sus vertientes: a) derecho a la tutela judicial efectiva en lo que hace al derecho a obtener una resolución motivada: la razón de ser fue que el juzgado de lo mercantil certificó como TEE el auto de 26 de octubre de 2009, despachando ejecución, cuando, de conformidad con los arts. 3.1, 4.1, 4.2, 5 y 6.1 del Reglamento $805 / 2004$, en relación con el art. 517 LEC, dicho auto no puede certificarse como TEE, sino solo la sentencia previa que dio lugar a él; b) derecho a un proceso con todas las garantías y a la proscripción de la indefensión, y ello por los siguientes motivos: la imposible certificación como título ejecutivo europeo de un auto despachando ejecución, como consecuencia además de un proceso previo en que ha existido un emplazamiento edictal. Argumenta el recurrente en amparo que no se respetaron las normas mínimas aplicables a los procedimientos y que sirven como condición para que las resoluciones obtengan la plena libertad de ejecución en territorio europeo según el Reglamento 805/2004 (entre ellas, emplazamiento personal, con proscripción del emplazamiento edictal).

El recurso de amparo núm. 442/2015 fue admitido a trámite por resolución de 30 de noviembre de 2015. En ambos recursos de amparo, y mediante otrosí digo, el recurrente solicitaba la suspensión parcial de la ejecución de título judicial núm. 695-2009 interesándose que la misma se disponga en 
relación con las actuaciones ejecutivas que conciernen al demandante en amparo don Christopher Frank Carandini Lee, también la suspensión del título ejecutivo europeo. Sin embargo, la Sala dictó los AATC 17/2016 y 19/2016, de 1 de febrero, denegando la suspensión solicitada en ambos casos.

Finalmente, el Tribunal Constitucional ordenó la acumulación de ambos recursos de amparo (recurso núm. 4657/2014 y núm. 442/2015), de manera que ambos fueron resueltos de manera simultánea en la misma Sentencia 26/2020, de 24 de febrero que es la que comentamos.

Mientras tanto, el Sr. Christopher Lee falleció el 7 de junio de 2015, y tanto el Juzgado de lo Mercantil núm. 1 de Burgos como el propio TC en ambos recursos de amparo admitieron la sucesión procesal del Sr. Lee en la persona de su viuda, a la que le reconocieron interés legítimo dado que la estimación o desestimación de dichos recursos, tendría un efecto directo en los intereses que corresponde defender a la Sra. Lee, designada testamentariamente como sucesora de su esposo, en el procedimiento de ejecución abierto. En palabras del TC: «hemos tenido ocasión de precisar que dicha legitimación activa se concede a toda persona cuyo círculo jurídico pueda resultar perjudicado por la violación de un derecho fundamental, aunque la violación no se produzca directamente en su contra (ATC 1193/1988, de 24 de octubre, y 58/2000, de 28 de febrero)» (ATC 206/2006, de 3 de julio, FJ 2).

\subsection{El comportamiento del tribunal inglés ante la solicitud de ejecución del TEE}

El 20 de enero de 2014, se registró ante la Queen's Division de la High Court of England and Wales la solicitud de ejecución de la resolución española certificada como TEE. Dos días después, se le notificó a la parte demandada a través de un despacho en Londres que se procedería a la ejecución a menos que tuvieran noticias antes del 31 de enero de 2014. Este fue el momento en que la parte demandada/ejecutada tuvo la primera noticia de la demanda. Respondió pidiendo veintiocho días para poder instruir a los abogados y adoptar la estrategia de defensa. El ejecutante se opuso y declaró que se procedería hacer cumplir la sentencia certificada sin previo aviso, a menos que la suma fuera pagada antes del 7 de febrero de 2014.

El 3 de febrero de 2014, los demandados solicitaron ante el juez inglés una suspensión de la ejecución de conformidad con el art. 23 del reglamento aduciendo que no se trataba de una reclamación no impugnada en virtud del art. 3.1 del Reglamento y el demandado instó a un bufete malagueño para que solicitara la anulación de las resoluciones españolas y del CTEE. El 3 de febrero de 2014 se dictó la orden de suspensión que fue notificada a la parte ejecutante. Tras el recurso pertinente del demandante frente a la suspensión de la ejecución, esta quedó confirmada por sentencia de la High Court of Justice, 
Chancery Division, de 6 de junio de $2018^{21}$, a la espera de que se resolvieran los recursos en España, entre ellos, los recursos de amparo.

En Inglaterra se intentó la oposición a la validez del CTEE español no solo por no haber observado los requisitos para la certificación del reglamento, sino porque el certificado contenía solo el nombre del deudor y el monto de la deuda, por lo que no era suficiente para proceder a la ejecución. El debate se centró en el carácter discrecional de la suspensión del procedimiento de ejecución por las circunstancias excepcionales del art. 23 c) del reglamento. Para ello se adujo que la denegación de una suspensión tendría un efecto catastrófico en el deudor porque lo llevaría a bancarrota. De otro lado, se argumentó que aunque el art. 21.2 del reglamento prohíbe la revisión judicial al tribunal de ejecución, no impide que tenga en cuenta la probabilidad de éxito de cualquier impugnación en el país de origen como un factor relevante en el ejercicio de la facultad discrecional, por lo que se pidieron informes al despacho de Málaga sobre la trascendencia de los recursos pendientes en España, a modo de juicio prospectivo de las posibilidades de éxito de los recursos. Aunque se le informó de que se había denegado la suspensión de la resolución y, por tanto, no había perdido su poder ejecutivo, el tribunal inglés aplicó su discrecionalidad para suspender la ejecución. A nuestro juicio, aunque la jueza inglesa tuvo que torturar el reglamento para suplir las deficientes actuaciones de ambas partes, consiguió mantener la suspensión recurriendo a su poder discrecional de suspensión, al considerando 17 y a la exigencia de los requisitos formales necesarios del certificado al faltarle cumplimentar algunas casillas. Funambulismo que de forma muy parecida realiza la Audiencia de Girona en su Auto de 10 de junio de 2020, como veremos posteriormente. En ambos casos la realidad fáctica y el principio político de la confianza mutua han sido determinantes para que actúe con garantías el principio de reconocimiento mutuo (distinción de Arenas García, 2010: 360-361).

\subsection{Fallo del TC}

\subsubsection{Interés jurídico y pedagógico de la sentencia del TC}

A nuestro juicio, la sentencia del TC, al margen de su relevancia jurídica como garante del derecho a la tutela judicial efectiva admitiendo la trascen-

21 Sentencia de la High Court of Justice, Chancery Division, de 6 de junio de 2018, Royal Courts of Justice, Rolls Building Fetter Lane, London, EC4A 1NL, Case No: CH-2017-000197; Neutral Citation Number: [2018] EWHC 1374 (Ch). 
dencia constitucional de ambos recursos de amparo, cumple también un objetivo pedagógico de enorme importancia para los operadores jurídicos. Implícitamente, confirma la idea de que, en las relaciones transfronterizas de naturaleza civil, la defensa de los derechos hay que agotarla siempre ante los tribunales de los Estados de origen, base del principio de reconocimiento mutuo europeo ${ }^{22}$. La representación jurídica, tanto la española como la inglesa, del Sr. Lee lo tenía claro, y actuaron en el convencimiento de que, ante una resolución española certificada como título ejecutivo europeo, solo se podía pedir en el extranjero la suspensión del procedimiento de ejecución si se hubiera ya iniciado, y siempre que se pudieran fundamentar los extremos del art. 23 del reglamento, quedando a la discreción del juez ejecutor la suspensión o no. Por ello, la defensa española del Sr. Lee recurrió en España con todas las armas del reglamento y el apoyo de la jurisprudencia del TJUE, sin conseguir resultado alguno. Ante la flagrante infracción de los derechos de defensa del demandado en los procedimientos declarativo y de ejecución, agravado por la certificación del TEE que le otorga libertad de ejecución sin posibilidad de control en el extranjero, agotó la penúltima posibilidad jurisdiccional de defensa del derecho fundamental planteando los recursos de amparo y antes de recurrir al TEDH.

La infracción del juez de Burgos al certificar una resolución notificada por edictos, lo que está expresamente prohibido por el reglamento (considerando 13) y confirmado por el TJUE ${ }^{23}$, la entendió el TC y entretejió la infracción del derecho europeo, no solo con la CE española, sino también con la CDFUE en los siguientes términos:

22 Debe recordarse que en el ámbito de aplicación del Reglamento «Bruselas I» el Tribunal de Justicia ha declarado en diversas ocasiones que el cauce natural para la defensa es el proceso de origen y que no hay que esperar a la fase de reconocimiento para invocar una lesión de este derecho (entre otras, Sentencia de 14 de diciembre de 2006, asunto C-283/05, ASML, ECLI:EU:C:2006:787).

23 Sentencia de 15 de marzo de 2012, asunto C-292/10, G. (ECLI:EU:C:2012:142) y Sentencia de 27 de junio de 2019, asunto C-518/18, RD, (ECLI:EU:C:2019:546). Esto no quiere decir que cuando el domicilio del demandado sea desconocido no pueda practicarse una notificación por edictos (Sentencia TJUE de 17 de noviembre de 2011, asunto C-327/10, Hypoteční banka, ECLI:EU:C:2011:745), sino que la que sentencia que se dicte en dichas circunstancias no puede certificarse como título ejecutivo europeo. En ese caso, y como veremos, el acreedor para hacer efectivo el crédito deberá recurrir a los mecanismos previstos en el Reglamento 1215/2012, que permite al deudor oponerse en fase de ejecución si se lesionó su derecho de defensa (art. 45). 
Este Tribunal estableció en la STC 232/2015, de 5 de noviembre, que el desconocimiento y preterición de esa norma de Derecho de la Unión, tal y como ha sido interpretada por el Tribunal de Justicia, puede suponer una 'selección irrazonable y arbitraria de una norma aplicable al proceso', lo cual puede dar lugar a una vulneración del derecho a la tutela judicial efectiva (STC 145/2012, de 2 de julio, FFJJ 5 y 6). Y, en este caso, la selección irrazonable concurre desde el momento en que el órgano judicial valora positivamente el ajuste de la notificación edictal a la LEC, sin tener en cuenta que no está ante un problema de validez genérica de la notificación por edictos, sino ante la suficiencia de este tipo de comunicación, correcta o incorrectamente realizada en términos de derecho nacional, de cara a la emisión de un certificado del TEE. La cuestión es que, en este caso, la doble filiación de los derechos de audiencia y de defensa, hubiera exigido un examen complejo por parte del órgano judicial, que en este caso no solo actúa como garante del art. 24.1 CE, sino también del art. 47 CDFUE, de modo que no bastaba con constatar que se cumplían los requisitos del primero, sino que también debía haber verificado que la resolución cuya certificación se solicitaba, respetaba el contenido y límites del artículo 47 de la Carta, en el sentido que les había atribuido el Tribunal de Justicia de la Unión Europea ${ }^{24}$.

De otro lado, la defensa inglesa del Sr. Lee consiguió la suspensión de la ejecución encontrando un tribunal permeable a sus argumentaciones como hemos podido comprobar en el relato de la sentencia de la High Court of Justice, Chancery Division, de 6 de junio de 2018. Los astros se alinearon en una estrecha colaboración, base ineludible para alcanzar una correcta defensa de los derechos.

\subsubsection{Priorización de la notificación personal para la ejecución de la sentencia en España}

\section{El TC concluye:}

que la notificación por edictos del auto despachando la ejecución, que se acuerda por providencia de 26 de abril de 2010, no fue una modalidad de notificación válida respecto del Sr. Carandini Lee, porque en ningún momento del procedimiento de ejecución, ni en la fase de apertura, ni una vez despachado el auto definitivo, el órgano judicial intentó en modo alguno la notificación personal de las actuaciones y resoluciones concernidas en el procedimiento a quien fue recurrente en amparo. Puede concluirse que el juez no agotó en absoluto los instrumentos de

24 La sentencia de la High Court of Justice, Chancery Division, de 6 de junio de 2018, recurre también a la CDFUE para fundamentar la suspensión de la ejecución del TEE certificado por el juez de Burgos. 
búsqueda a su alcance que, como alega el recurrente en su demanda de amparo, eran particularmente accesibles habida cuenta de la notoria popularidad de don Christopher Carandini Lee.

De hecho, los abogados ingleses del demandante consiguieron hallar e informar fácilmente al demandado en Londres sobre el inicio de la ejecución de la sentencia. Advierte el TC de la autonomía de los procedimientos ordinarios y de ejecución sin que las notificaciones infructuosas del primero eximan del esfuerzo ab initio por parte del tribunal ordinario para observar la totalidad de las garantías procesales previstas en el art. 24.1 CE. Conclusión a la que llega tras una consistente revisión de la jurisprudencia constitucional anterior, que, podemos decir, hoy queda bendecida por la reciente sentencia TEDH de 15 de diciembre de 2020 en la que se condena a España por violación del art. 6 del Convenio Europeo de Derechos Humanos. La sentencia del TEDH es el resultado del rechazo de un recurso de amparo ante el Tribunal Constitucional al considerar que el caso no tenía la "especial relevancia constitucional» requerida $^{25}$. La Corte de Estrasburgo, sin embargo, ha considerado que, tal y como planteaban los demandantes cuya primera noticia del desahucio les llegó por los apuntes de embargo en su cuenta corriente, las autoridades españolas no hicieron los esfuerzos suficientes para asegurarse de que, a la pareja, de finlandesa y gambiano, se le había comunicado efectivamente la puesta en marcha de un procedimiento de desahucio en su contra por un apartamento situado en Málaga. El TEDH concluye que el hecho de que la LEC establezca la dirección de la casa alquilada como dirección por defecto para enviar documentos no exime a los juzgados y tribunales de su obligación de informar a los afectados de los procedimientos de desahucio. Ordena, por tanto, a España a pagar a los demandantes 2400 euros en concepto de daños no pecuniarios y 8417,50 euros por costas y gastos, rebajando así las expectativas de la pareja, que había pedido 20840 euros en daños pecuniarios —algo que el TEDH no ha apreciado-, otros 20000 en daños no pecuniarios y 10532,50 en costas y gastos. Esta misma línea jurisprudencial se mantiene en 2021 en la STEDH de 19 de enero, que resuelve sobre una ejecución hipotecaria en rebeldía. La Corte de Estrasburgo ha concluido que las autoridades judiciales españolas no fueron diligentes a la hora de informar al demandante sobre los procedimientos de ejecución hipotecaria, por lo que no tuvo «una oportunidad razonable» de participar en ellos, indicando asimismo que tampoco se le dio una "oportunidad razonable» para exponer sus argumentos en un nuevo juicio. Se trataba de dos ciudadanos neerlandeses con domicilio

25 Auto 98/2015, de 1 de junio, ECLI:ES:TC:2015:98A 
en Alemania, aunque en el préstamo hipotecario constaba un domicilio en España. El TEDH ha reprochado al juzgado de primera instancia que «solo hizo un intento de entregar personalmente las notificaciones». Después delegó en el juzgado de paz, que acudió a Correos, pero sin éxito porque — según el servicio postal- el primer tribunal no dio detalles suficientes de la dirección indicada. A pesar de ello, el juzgado de primera instancia optó por publicar las notificaciones en su boletín oficial, en lugar de buscar la dirección correcta en sus sistemas internos.

Sentencias como estas avalan, como afirma Garcimartín Alférez (2006: 190-198), que el art. 6 CEDH es el estándar internacional en materia de ejecución de resoluciones extranjeras.

\subsubsection{Exigencias de la notificación en el proceso español para la ejecución en otro Estado de la UE}

La ejecución del CTTE en virtud del Reglamento 805/2004 como fórmula más avanzada es alternativa a las otras formas de ejecución de las resoluciones extranjeras (art. 27). Nos preguntamos entonces qué hubiera pasado si el demandante hubiera solicitado el exequátur en Inglaterra en virtud del Reglamento 44/2001, aplicable al caso al haberse planteado la demanda antes del 10 de enero de 2015, y no ser de aplicación el Reglamento 1215/2012 (art. 66.2). Dependerá de las circunstancias. Pero, en principio, y siendo preceptivo el trámite del reconocimiento previo para conseguir la ejecutividad, el demandado podría oponerse a dicho reconocimiento por defecto de notificación (art. 34.2). Ahora bien, la notificación por edictos, en este caso, no es óbice para solicitar el reconocimiento y la ejecución, solo que se requiere demostrar que se trataba de una rebeldía a la fuerza y no de conveniencia ${ }^{26}$. Una notificación defectuosa quedaría subsanada por el conocimiento del demandado y la posibilidad de recurrir y que esta posibilidad de recurso permita la revisión plena fáctica y jurídica, aunque no implique una retroacción de las actuaciones ${ }^{27}$. La notificación por edictos no es oponible siempre que se hayan realizado todas las investigaciones que exigen los principios de diligencia y buena fe para encontrar al demandado ${ }^{28}$.

26 Entre otras, SSTUJE de 11 de junio de 1985, asunto C-49/84, Debaecker y de 14 de diciembre de 2006, asunto C-283/05, ASML, ECLI:EU:C:1985:252 yECLI:EU:C:2006:787, respectivamente.

27 Sentencia TJUE de 7 de julio de 2016, asunto C-70/15, Lebek, ECLI:EU:C:2016:524.

28 El TJUE en una consolidada jurisprudencia viene afirmando que el derecho de la Unión no se opone a que se dicte una sentencia en rebeldía frente a un demandado al 
En estas circunstancias, nos cabe la duda de si el juez inglés, con competencia en este caso para controlar la ejecutividad de la resolución española en el trámite de exequátur si no hubiera sido certificada, hubiera aceptado o no la oposición del demandado por lesión de sus derechos de defensa. Es cierto que, si el juez de Burgos no intentó la notificación personal y no agotó todas las posibilidades para encontrar al Sr. Lee, podemos entender que estamos ante una rebeldía a la fuerza por lo que, si se hubiera solicitado en Inglaterra el exequátur conforme al Reglamento 44/2001, quizás podría haber prosperado el motivo de denegación del art. 34.2 o quizás no, y se hubiera ejecutado, pues dependerá del umbral protector del derecho inglés aun debiendo aplicar los límites impuestos por la jurisprudencia del TJUE. Afortunadamente, en este caso, el Reglamento 805/2004 le ha permitido al demandado conseguir la suspensión de la ejecución en Inglaterra y proteger sus derechos por el juez de origen, en este caso el TC español. De aquí que el déficit de armonización sustantiva y procesal entre los Estados miembros de «Bruselas I bis», que se ha aducido como justificación para no eliminar el control de la resolución en el Estado de ejecución (Sánchez Lorenzo, 2019), pueda volverse en contra de la protección de las garantías procesales cuando dicha protección de los valores esenciales se llegue a encontrar más asegurada en el Estado de origen que en el Estado de ejecución.

En aplicación del Reglamento «Bruselas I bis», la solución no hubiera sido diferente ${ }^{29}$; la sentencia española hubiera tenido eficacia ejecutiva directa en Inglaterra, lo que significaría que, en ningún caso, habría requerido trámite de reconocimiento previo o exequátur para iniciar el procedimiento de ejecución, al margen de que hubiera sido certificada o no en virtud del Reglamento 805/2004. Ahora bien, en el procedimiento de ejecución inglés el demandado podría haberse opuesto en virtud del art. 45.1.b) del Reglamento 1215/2012. Sin embargo, al haber sido certificada como TEE, dicha oposición del demandado ya sería imposible porque el control del cumplimiento de las normas mínimas y del respeto del derecho de defensa, lo debe realizar el juez de origen.

que, ante la imposibilidad de localizare, se notificó el escrito de demanda mediante un edicto siempre que el órgano jurisdiccional que conoce del asunto se haya cerciorado antes de se realizaron todas las averiguaciones que exigen los principios de diligencia y buena fe para encontrar a dicho demandado (SSTJUE de 17 de noviembre de 2011 y de 15 de marzo de 2012, ya citadas).

29 Véase el art. 67 del Acuerdo sobre la retirada del Reino Unido e Irlanda del Norte de la Unión Europea y de la Comunidad Europea de la Energía Atómica (DO 29, de 31 de enero de 2020, p. 7). 
De aquí la trascendencia de la irregular actuación del juez de Burgos cuando deniega la solicitud de revocación del CTEE, cuyo auto de denegación se convierte en la base del segundo recurso de amparo y cuya trascendencia constitucional asume el propio $\mathrm{TC}^{30}$. El juez de Burgos debió comprobar que el procedimiento no cumplía con las normas mínimas que establece el capítulo III del Reglamento 805/2004 y, por tanto, no debió certificar su resolución en primer lugar o, al menos, debió enmendar su error aceptando la solicitud de revocación para evitarle la indefensión al demandado. Normas mínimas, que, como ya se ha advertido, no son de aplicación directa ni tienen los Estados la obligación de incorporarlas si no fueran derecho procesal interno.

Lo interesante de la sentencia del TC es el encaje que consigue tejer con los hilos del derecho europeo y los del art. $24 \mathrm{CE}$ en los siguientes términos:

Todo lo anterior nos lleva a concluir que, incluso aunque la notificación edictal hubiera sido efectuada correctamente según los parámetros de nuestra jurisprudencia constitucional, que no lo fue porque en ningún momento el órgano judicial intentó siquiera la notificación personal, ni la averiguación del domicilio del deudor, la certificación del TEE no se hubiera ajustado al derecho de la Unión, porque en este caso el domicilio del deudor era desconocido. Por tanto, de la inadecuada aplicación del derecho de la Unión se deriva, en el supuesto que ahora nos ocupa, una clara vulneración del derecho a la tutela judicial efectiva (art. 24.1 CE), por errónea aplicación de la norma que, a mayor abundamiento, implica una infracción clara del derecho de defensa (art. 24.1 CE) del recurrente en amparo ${ }^{31}$.

De no haber realizado este encaje, le hubiera sido imposible al TC entrar en asuntos de legalidad ordinaria en cuanto a la aplicación del reglamento. Aunque el encaje es débil y los internacional-privatistas hubiéramos deseado más munición, sin embargo, ha sido suficiente ante el caso concreto. No ha hecho falta cuestión prejudicial ante el TJUE ni tener que terminar en el $\mathrm{TEDH}^{32}$, como hubiera sucedido si la sensibilidad del TC hubiera sido otra.

Posteriormente, el TC dictó el auto de 21 de septiembre de $2020^{33}$, en el que resuelve negativamente la solicitud de aclaración del fallo de la Sentencia en cuanto exige el compareciente que la retroacción de las actuaciones no se proyecte más que a una de las partes del procedimiento de instancia, esto es, exclusivamente al que fuera recurrente en amparo, partiendo del

30 Página 36 de la sentencia.

31 Página 39 de la sentencia.

32 Para el análisis de otras vías de control de las garantías procesales en el ámbito del reconocimiento mutuo, véase, Guzmán Zapater (2012: 141-160).

33 Auto 102/2020, de 21 de septiembre, ECLI:ES:TC:2020:102A. 
presupuesto de que al resto de las partes en la ejecutoria no se les ha vulnerado derecho fundamental alguno. Sin embargo, el TC dice claramente que los efectos que deban derivarse de la sentencia en relación con cada uno de los obligados solidarios, es una cuestión que deberá determinar el órgano judicial de instancia.

Dicho de otro modo, nuestro cometido no consiste en interpretar las normas procesales y determinar el concreto modo en que la repetición del procedimiento de ejecución afecta a los intereses de los ejecutados que no fueron recurrentes en amparo. Es competencia del órgano judicial de instancia dar cumplimiento a la sentencia resolutoria del recurso de amparo y, una vez reabierto el procedimiento de ejecución, velar porque el nuevo procedimiento respete los derechos fundamentales de quien fue recurrente en amparo y de todas las partes en dicho procedimiento. $\mathrm{Y}$ es en aquella sede en la que han de aclararse los efectos concretos de la reapertura del procedimiento de ejecución sobre los distintos ejecutados.

Finalmente, por providencia de 6 de junio de 2020, el juez de lo mercantil de Burgos considera improcedente la solicitud de la subsanación pretendida por el demandante del CTEE al no reunir los requisitos del art. 14 del Reglamento $805 / 2004$.

\subsection{4. ¿Por qué solicita el demandante la certificación del auto despachando la ejecución y no la resolución declarativa de la que trae causa?}

Otro de los debates del reglamento, y que se aborda en la demanda de amparo, es el relacionado con las resoluciones susceptibles de certificación. En este caso, el demandante solicita la certificación del auto despachando ejecución al ser la resolución que fija la cantidad ya que una condena de cantidad que no sea líquida, no es susceptible de ser certificada (art. $4.2 \mathrm{del}$ reglamento) ${ }^{34}$. Como la resolución declarativa solo condenaba al demandado al pago de una indemnización de forma genérica cuya determinación no era posible con una simple operación aritmética (art. 219 LEC), no era susceptible, por tanto, de certificación.

Según el art. 4.1: «se entenderá por resolución, cualquier decisión adoptada por un tribunal de un Estado miembro con independencia de la denominación que recibiere, tal como auto, sentencia, providencia o mandamiento de ejecución, así como el acto por el cual el secretario judicial liquidare las costas del proceso». Esta noción autónoma de resolución debe ser encajada

34 Que el reglamento solo cubra los créditos pecuniarios ha sido objeto de críticas (Boschiero, 2003: 415). 
en cada sistema procesal a fin de concretar qué tipo de decisiones, cumplidos el resto de presupuestos, pueden ser certificadas como título ejecutivo europeo ${ }^{35}$. Y en nuestro ordenamiento una cuestión que podría debatirse es si el auto despachando ejecución puede certificarse como TEE, es decir, si puede considerarse como una resolución ejecutiva sobre un crédito no impugnado conforme al Reglamento 805/2004, como así lo entendió el juez de Burgos. Al respecto, la doctrina mayoritaria se ha pronunciado en sentido negativo puesto que el auto que despacha ejecución no declara la exigibilidad de una deuda líquida, ni es una resolución ejecutable sino, como afirma Martín Mazuelos: «una decisión de iniciar la ejecución de otra anterior» (Martín Mazuelos, 2020: 12-14; en sentido análogo, Gascón Inchausti, 2005: 80; Marchal Escalona, 2020: 37). Sin embargo, no vemos impedimento en incluir el auto que despacha ejecución en los procesos especiales previstos en nuestra LEC, así como el que liquida la deuda cuando no estuviera determinada en el declarativo, como debió seguirse en el caso comentado. Efectivamente, si se hubiera seguido el cauce de los arts. 712 y ss., hubiera habido un procedimiento contradictorio para determinar la cantidad adeudada que completaría la resolución declarativa ${ }^{36}$. Si el demandante hubiera obviado el certificado TEE y hubiera solicitado el reconocimiento en Inglaterra de la resolución española en virtud del Reglamento 44/2001, aplicable temporalmente al caso como hemos visto, hubiera tenido que reconocer ambas resoluciones para iniciar posteriormente el procedimiento de ejecución en Inglaterra. Resulta extraño entonces que ambas resoluciones no formen un todo jurídico sancionador susceptible de certificación como TEE. Sin embargo, el juez de Burgos obvió este procedimiento. No obstante, el TC no aborda este aspecto, al no reconocerle trascendencia constitucional a la resolución certificable según el reglamento, extremo que, a nuestro juicio y al parecer también del TC, resulta ser un aspecto de legalidad ordinaria cuando afirma: "La cuestión concreta que debió haberse planteado el Juzgado de lo Mercantil núm. 1 de Burgos, más allá de las consideraciones sobre si el auto despachando la ejecución era un título ejecutivo en el sentido del Reglamento» ${ }^{37}$.

Hay que afirmar que en la práctica española son frecuentes los supuestos en los que se certifican los autos despachando ejecución que determinan las cantidades a pagar o a devolver, y donde no hay debate, bien por la imposibilidad

35 Comprobamos una vez más el problema de la dependencia del derecho europeo de los derechos nacionales estudiado por Arenas García (2012: 69-93).

36 Cobo Sáenz (2006: 258) también incluye entre las resoluciones certificables la providencia ex art. 714.1 LEC.

37 Página 38 de la sentencia. 
de oposición o bien por la ausencia de causa oponible; y en otros, se certifican resoluciones donde no ha habido impugnación en el declarativo y, sin embargo, sí en la fijación de la condena (Echezarreta Ferrer, 2020: 51-60). En una futura revisión del Reglamento 805/2004 debería plantearse el debate de la ampliación de la certificación de las resoluciones dictadas en cualquier tipo de procedimiento, como hemos visto más arriba. A nuestro juicio si cualquier resolución sobre condena al pago, impugnada o no, entrara dentro del ámbito de aplicación con las debidas garantías, el debate sobre la posibilidad de certificar el auto despachando ejecución, desaparecería.

\section{ESPAÑA COMO ESTADO EJECUTOR DE TÍTULOS EJECUTIVOS EUROPEOS EN VIRTUD DEL REGLAMENTO}

Una revisión de la práctica judicial española arroja un balance positivo de la ejecución en España de los TEE certificados en el extranjero. En general, las autoridades judiciales españolas tienen asumida la imposibilidad de aceptar la oposición a la ejecución de una resolución extranjera certificada, ni de controlar las garantías procesales observadas en el procedimiento extranjero

2020 nos ha brindado la oportunidad de comprobar la madurez de la justicia española en este sentido con el auto de la AP de Girona de 10 de junio ${ }^{38}$, que resuelve el recurso de apelación frente a la impugnación de la decisión del juzgado de instancia que decide negativamente la oposición a una ejecución de un TEE expedido por el Tribunal de Comercio de Amberes el 10 de enero de 2018 y que trae causa de la sentencia del mismo Tribunal de 30 de septiembre de 2015 dictada en rebeldía con una condena provisional de $100000 €$. Con base en este TEE se despachó ejecución por el juzgado de instancia a petición de la sociedad belga y de una persona física, ambos con domicilio en Bélgica, sobre un principal de $100000 €$ y de $30000 €$ más por intereses y costas provisionales.

38 Auto de la AP de Girona 243/2020, de 10 de junio (Cendoj: 17079370012020200212). En 2020 también se ha dictado el auto de la AP de Cartagena 24/20, de 21 de enero (Cendoj: 30016370052020200053 ) que resuelve sobre la caducidad de la acción ejecutiva dado que la sentencia francesa adquirió firmeza el 17 de septiembre de 2012, se certificó como TEE el 30 de abril de 2014, y se solicitó la ejecución el 30 de noviembre de 2017, en aplicación del art. 815 (sic), 518 LEC para salvar el error. La cuestión que se plantea es si el plazo de caducidad comienza a contar desde que la sentencia se dicta o desde la certificación. En este caso la AP de Cartagena ha entendido que es a partir de la resolución de base. Solución que también defienden Garcimartín Alférez (2006: 116-120) y Gascón Inchausti (2005: 109). 
Con posterioridad a la presentación del recurso, el demandado presentó ante la AP de Girona la traducción jurada de una sentencia dictada por la Corte de Apelaciones de Amberes de fecha 12 de septiembre de 2019 en la que se tenía por debidamente admitido un recurso de apelación contra la sentencia contenida en el TEE. La Audiencia de Girona, en auto de 9 de diciembre de 2019, desestimó la petición sobrevenida del demandado para que se archivara la apelación con base en que el TEE debía ser rectificado por cuanto el contenido de la sentencia certificada por el mismo debía ser alterada por el dictado de aquella otra sentencia de apelación de la Corte de Apelación de Amberes el 12 de septiembre de 2019. La audiencia la desestimó basándose en que el tribunal español no tenía competencia para rectificar el TEE de acuerdo con el art. 10 del Reglamento 805/2004.

La Audiencia parte de un contenido pedagógico que trasluce un conocimiento claro de la esencia del Reglamento 805/2004, relatando con gran exactitud los conceptos normativos más sobresalientes del reglamento. Finalmente, recurre al art. 23.c) del reglamento, declarando la excepcionalidad de la situación al comprobar que la decisión ha sido impugnada en origen y, por tanto, se han modificado de facto los datos esenciales del formulario de certificación de la sentencia de instancia belga de 30 de septiembre de 2015 (concretamente en los epígrafes 6, 7, 12.1, 13.3 y 13.4). Ante tal situación, actúa igual que el juez inglés en el caso resuelto por el TC que vimos anteriormente, suspendiendo la ejecución, a la espera de la revocación en Bélgica del CTEE fruto de la nueva sentencia derivada del recurso ante el tribunal de Amberes.

Lo único cuestionable es la actuación de oficio de la Audiencia en la aplicación del art. 23 c), ya que la suspensión la debió solicitar el deudor/ apelante que solo reclama que se examine si el TEE reúne los requisitos legales para llevar aparejada la ejecución. Desde nuestro punto de vista, la actuación judicial, aunque algo creativa porque se arroga una competencia que no tiene, equilibra la justicia del caso y el funcionamiento del reconocimiento mutuo del reglamento TEE. Con esta decisión no se le cierra la puerta al ejecutante, que podría volver a presentar un nuevo CTEE con la nueva resolución de base del tribunal de Amberes si es que consiguiera la certificación (difícil ya, ante la impugnación del crédito), o solicitar la ejecución directa en virtud del Reglamento 1215/2012, que presumimos sería de aplicación. Sin embargo, peca de ser una interpretación excesivamente voluntarista de la normativa europea que en ocasiones se impone. Quizás, como ya hemos afirmado, este podría ser otro extremo para el debate en una futura revisión del reglamento, debiendo valorar las posibilidades de actuación de oficio por parte del juez ejecutor en cuanto a la suspensión de la ejecución cuando no hubiera sido solicitada por el ejecutado. 


\section{CONCLUSIONES}

Llegados a este punto, y como conclusiones más destacables de nuestro estudio, hay que afirmar que:

$1^{\circ}$. La práctica española de 2020 sobre la aplicación del Reglamento 805/2004 viene a confirmar su madurez y el avance del principio de reconocimiento mutuo, comprobando su escasa litigiosidad. Con las garantías procesales existentes en origen, al menos en España, se puede impedir poner en circulación una resolución cuya ejecución en el extranjero atente los derechos de defensa del demandado.

$2^{\circ}$. La STC y el AAP de Girona comentados contribuyen a lanzar un mensaje de seguridad jurídica y confianza tanto para acreedores-ejecutantes como para deudores-ejecutados puesto que la celeridad en el cobro de las deudas se realiza con garantías del respeto de los derechos de defensa. En las resoluciones comentadas el reconocimiento mutuo funcionó en la bilateralidad España-Reino Unido y Bélgica-España, aunque el futuro de la primera tenga los días contados. Su función pedagógica convierte a ambas resoluciones en el paradigma español del reconocimiento mutuo.

$3^{\circ}$. Se debería extender la regulación del Reglamento 805/2004 a los créditos impugnados cuya calificación en la práctica requiere de un consumo procesal innecesario, ya que la impugnación por parte del demandado asegura más certeramente la observancia de las garantías de la defensa en el proceso de origen, que la no impugnación. Pero para ello es necesario abrir el debate sobre diferentes cuestiones: de un lado, la aplicación directa de las normas mínimas como normas procesales especiales para supuestos transfronterizos al objeto de extender las garantías procesales entre aquellos Estados miembros que no las contengan en sus ordenamientos internos y así dar un paso más en el reconocimiento mutuo. Por otra parte, aclarar las dudas sobre las resoluciones susceptibles de certificación y, en particular, sobre el auto despachando ejecución, al menos cuando es el procedimiento que determina la cantidad a pagar o a devolver.

$4^{\circ}$ No creemos que atentaría los principios del reconocimiento mutuo conceder mayor poder de actuación de oficio al juez ejecutor en el ámbito de la suspensión de la ejecución cuando se le acredite una lesión de los derechos de defensa del ejecutado que esté revisándose en el Estado de origen. Podría salvar los errores que este cometiera y proteger sus derechos sin invadir las competencias de control que únicamente corresponde al juez que conoce del asunto en origen.

$5^{\circ}$. Partiendo de la situación descrita creemos que, ante la improbable reforma del Reglamento 805/2004, es el momento de consolidar el reconocimiento mutuo en las materias del Reglamento 1215/2012 e incorporarlo 
como alternativo dentro del mismo cuerpo normativo, tal y como funciona en el Reglamento 4/2009 o en el Reglamento 2201/2003 (sustituido por el Reglamento 2019/1111). Requeriría tan solo una actuación de Dinamarca si es que quisiera extender dichos artículos.

Con todo ello, dotaríamos de un poco más de coherencia legislativa al ingente conjunto normativo, evitaríamos tener que recurrir a argucias para certificar los créditos impugnados y le haríamos un gran favor a los docentes y a los profesionales.

\section{Bibliografía}

Arenas García, R. (2010). Abolition of exequatur: problems and solutions. Mutual recognition, mutual trust and recognition of foreign judgments: too many words in the sea. Yearbook of Private International Law, 12, 351-375.

Arenas García, R. (2012). Reglamentos europeos y Derecho procesal nacional: delimitación e interacción. En C. Parra Rodríguez (dir). Nuevos reglamentos comunitarios y su impacto en el Derecho Catalán (pp. 69-93). Barcelona: Bosch.

Barcala Fernández de Palencia, A. (2020). La última actuación de Cristopher Lee (a propósito del Reglamento comunitario 805/2004). Diario La Ley, 9634. Disponible en: https://bit.ly/2ZLVgDp.

Biagioni, G. (2007). Aspetti evolutivi nella disciplina comunitaria dell'esecuzione delle sentenze straniere: i regolamenti (CE) n. 44/2001 e n. 805/2004. En G. Carella. Cooperazione giudiziaria ed eficacia delle sentenze: problematiche di diritto internazionale europeo (pp. 199-214). Bari: Cacucci.

Boschiero, N. (2003). The Forthcoming European Enforcement Order. Towards a European Law Enforcement Area. Rivista di Diritto Internazionale, 2, 394-425.

Cobo Sáenz, J. F. (2006). El encaje del Título ejecutivo europeo en el Derecho procesal del Estados miembros: ¿necesidad de ajustes? En S. Adroher Bioscar, B. Campuzano Díaz (coords.). Hacia la supresión del exequatur en el espacio judicial europeo: El Titulo ejecutivo europeo (pp. 245-263). Sevilla: Universidad de Sevilla.

Cuartero Rubio, M. ${ }^{a}$ V. (2019). Reconocimiento mutuo de resoluciones judiciales y diálogo judicial internacional en la protección de los derechos fundamentales: cuando el Tribunal Constitucional es «Tribunal del Estado de origen». En D. González Herrera (coord.) y J. M. Pérez de Nanclares (dir.). El diálogo judicial internacional en la protección de los derechos fundamentales (pp. 225-237). Valencia: Tirant lo Blanch.

Cuartero Rubio, M. ${ }^{a}$ V. (2020). Cooperación judicial civil en la Unión Europea y tutela en origen de derechos fundamentales. Pamplona: Aranzadi.

Echezarreta Ferrer, M. (2020). El Reglamento 805/2004 sobre el Título ejecutivo europeo: Catorce años de aplicación en España. En P. Domínguez Lozano (dir.) 
y M. a J. Elvira Benayás (coord.). Derecho internacional privado europeo: Diálogos con la práctica (pp. 23-64). Valencia: Tirant lo Blanch.

Garau Sobrino, F. (2004). La declaración de ejecutividad automática: ¿hacia una nueva teoría general del exequátur? Anuario Español de Derecho internacional Privado, 4, 91-116.

Garcimartín Alférez, F. J. (2006). El título ejecutivo europeo. Navarra: Thomson-Civitas.

Gascón Inchausti, F. (2005). El Título ejecutivo para créditos no impugnados. Navarra: Thomson-Aranzadi.

Gascón Inchausti, F. (2017). El orden público como motivo de denegación de la ejecución al amparo del Reglamento Bruselas I bis. En C. Otero García-Castrillón (dir.). Justicia civil en la Unión Europea. Evaluación de la experiencia española y perspectivas de futuro (pp. 117-141). Madrid: Dykinson.

González Campos, J. D. (2005). Reconocimiento y ejecución de decisiones judiciales extranjeras y respeto de los derechos humanos relativos al proceso. En M. Vargas Gómez-Urrutia, A. Salinas de Frías (coords.). Soberanía del Estado y Derecho internacional. Homenaje al prof. J. A. Carrillo Salcedo (pp. 695-716). Sevilla: Universidad de Sevilla.

Guzmán Zapater, M. (2012). Supresión del exequátur y tutela de derechos fundamentales. Articulación en el sistema español. En A. Borrás Rodríguez, G. Garriga Suau (eds.). Adaptación de la legislación interna a la normativa de la Unión Europea en materia de Cooperación Civil, Homenaje al Prof. Dr. Ramón Viñas Farré (pp. 141-160). Madrid: Marcial Pons.

Jiménez Blanco, P. (2018). La ejecución forzosa de las resoluciones en el marco de los Reglamentos europeos. Revista española de Derecho internacional, 1, 101-125. Disponible en: http://dx.doi.org/10.17103/redi.70.1.2018.1.04.

Marchal Escalona, N. (2020). El recurso de amparo: la última oportunidad para la protección de los derechos fundamentales de defensa frente a la expedición de un título ejecutivo europeo. (Comentario a la Sentencia del TC 26/2020, de 24 de febrero). Revista Electrónica de Estudios Internacionales, 39, 32-38. Disponible en: https://doi.org/10.17103/reei.39.18.

Martín Mazuelos, F. J. (2020). El decreto de la Administración de Justicia y el auto despachando ejecución, como títulos ejecutivos europeos para créditos no impugnados. Bitácora Millenium Derecho internacional Privado, 12. Disponible en: http://milleniumdipr.com.

Rodríguez Vázquez, M. a A. (2005). El título ejecutivo europeo. Madrid: Colex.

Rodríguez Vázquez, M. ${ }^{a}$ A. (2006). El encaje del Título ejecutivo europeo en el Derecho procesal español. En S. Adroher Biosca, B. Campuzano Díaz (coords.). Hacia la supresión del exequátur en el espacio judicial europeo: el Título ejecutivo europeo (pp. 193-218). Sevilla: Universidad de Sevilla.

Rodríguez Vázquez, M. ${ }^{a}$ A. (2016a). Los requisitos para certificar una resolución como Título ejecutivo europeo y los derechos de defensa del deudor. La Ley/ Unión Europea, 35, 1-11. 
Rodríguez Vázquez, M.a A. (2016b). El concepto autónomo de crédito no impugnado del Reglamento sobre el Título ejecutivo europeo. La Ley/Unión Europea, 40, $1-7$.

Sánchez Lorenzo, S. (2019). Cincuenta años de Derecho Internacional Privado de la Unión Europea: el lado oscuro. En C. Esplugues Mota, P. Diago Diago y P. Jiménez Blanco (eds.). Cincuenta años de Derecho Internacional Privado de la Unión Europea en el diván (pp. 53-86). Valencia: Tirant lo Blanch.

Seatzu, F. (2008). Le garanzie del diritto alla difesa del debitore en el Regolamento n. $805 / 2004$ istitutivo del titolo esecutivo europeo per i creditti nono contestati. En N. Boschiero y P. Bertoli (eds.). Verso un ordine comunitario del proceso civile (pp. 45-69). Nápoles: Scientifica. 